\title{
VERDAD, METAFÍSICA Y EPISTEMOLOGÍA. OBSERVACIONES SOBRE LA NEUTRALIDAD DE LA VERDAD
}

\author{
José ANDrés Forero MORA \\ doi:10.11144/Javeriana.uph32-64.vmte
}

\begin{abstract}
RESUMEN
El presente texto pretende mostrar que la verdad es neutral con respecto a la metafísica y a la epistemología, esto es, que para hacer un análisis satisfactorio de la manera como cotidianamente usamos el discurso de verdad no es necesario aludir a la naturaleza del mundo ni a la naturaleza de nuestras capacidades epistémicas. Para esto, en primera instancia se explicitan las intuiciones de sentido común que parecen acercar la verdad a la metafísica o a la epistemología (sección 1); posteriormente, se analiza la función que el predicado «es verdadero» cumple dentro de nuestro lenguaje natural (sección 2); por último, con base en este análisis, se retoman las intuiciones mencionadas con el fin de indagar por su carácter intuitivo y la supuesta relación con la metafísica y la epistemología.

Palabras clave: verdad; aserción; teoría prooracional; teoría de la correspondencia

\footnotetext{
Corporación Universitaria Minuto de Dios y Universidad de los Andes, Bogotá, Colombia. Correo electrónico: jforero@uniminuto.edu

Para citar este artículo: Forero Mora, J.A. (2015). Verdad, metafísica y epistemología. Observaciones sobre la neutralidad de la verdad. Universitas Philosophica, 32(64), pp. 283-312, ISSN 0120-5323, ISSN en línea: 2346-2426, doi: 10.11144/Javeriana.uph32-64.vmte

Agradezco a los profesores Tomás Barrero, Miguel Ángel Pérez, Carlos Cardona, Santiago Amaya, Laura Giraldo, Alfonso Castell e Indalecio García por sus comentarios a versiones anteriores del texto. También agradezco especialmente a la profesora María José Frápolli por su lectura, por su amable disposición para discutir las ideas que aquí se encuentran expuestas y por sus lúcidas sugerencias. Los persistentes errores, por supuesto, son solo responsabilidad mía.
} 


\title{
TRUTH, METAPHYSICS AND EPISTEMOLOGY. SOME REMARKS ON NEUTRALITY OF THE TRUTH
}

\author{
José ANDRÉs Forero MORA
}

\begin{abstract}
This paper aims to show that truth is neutral with respect to metaphysics and epistemology. In other words, the paper states that in order to make an analysis about our daily use of truth discourse, it is not necessary to refer to neither the nature of the world nor the nature of our epistemic capacities. The text is composed by three sections. In the first one, it makes explicit the common-sense intuitions which seem to bring truth to either metaphysics or epistemology. In the second one, the text analyzes the role of the predicate «is true» in our natural languages. In the third section, the intuitions aforementioned are considered with the purpose of examining its intuitive status and its alleged relationship with both metaphysics and epistemology.
\end{abstract}

Key words: truth; assertion; prosentential theory; correspondence theory 
Donde nuestro lenguaje hace presumir un cuerpo y no hay un cuerpo, alli, quisiéramos decir, hay un espiritu.

Ludwing Wittgenstein

\section{Introducción: La noción de verdad y las intuiciones de sentido común}

LA IMPORTANCIA QUE LAS INTUICIONES DE SENTIDO COMÚN deben tener dentro una reflexión filosófica sobre la verdad es sugerida de manera notable por dos clásicos de la filosofía analítica: John Austin y Frank Ramsey. El primero, en su célebre artículo "Truth" (1950) sostiene que "una teoría de la verdad es una serie de perogrulladas"; el segundo, por su parte, afirma en The Nature of Truth (1927): "[verdad] es una palabra que todos entendemos, pero si tratamos de explicarla podemos fácilmente vernos envueltos, como lo muestra la historia de la filosofía, en un laberinto de confusión". La discusión contemporánea acerca de la verdad tampoco se da totalmente de espaldas al sentido común. De hecho, varias de las concepciones que suelen ser agrupadas bajo la etiqueta $«$ deflacionismo» ${ }^{1}$ (deflationism) encaminan gran parte de sus esfuerzos a conciliar un análisis lógico-lingüístico del predicado «es verdadero» con las intuiciones de sentido común que guardamos en torno a la noción misma de verdad.

Son diversas las intuiciones que hay sobre la noción en cuestión. Algunos filósofos se han atrevido a referirse a ellas como las obviedades o perogrulladas acerca de la verdad. Sin embargo, no todos aquellos que intentan conciliar la reflexión filosófica acerca de la verdad con el sentido común están pensando exac-

1 Como bien lo muestra Frápolli (2013, pp. 9-11), «deflacionismo» es un término ambiguo que no agrupa posiciones homogéneas. De acuerdo con Armour-Garb y Beall (2005, pp. 1-2), este término ha sido frecuentemente caracterizado de forma negativa para agrupar a todas aquellas concepciones que niegan que la verdad sea una propiedad sustantiva y que, en consecuencia, posea una naturaleza subyacente que tengamos que descubrir. Como lo advierten los dos autores, esta definición se hace bastante imprecisa y, por ello mismo, inútil si se desea hacer una discusión detallada acerca del significado de «deflacionismo» y de las distintas teorías que frecuentemente se agrupan bajo esta etiqueta. En este escrito la intención no es definir qué es deflacionismo ni discutir si hay o no una definición adecuada de él. 
tamente en el mismo conjunto de intuiciones ${ }^{2}$. No existe un común acuerdo con respecto a cuántas ni cuáles son exactamente, aunque parece que hay por lo menos un par en las que coinciden. No es la pretensión de este escrito hacer una lista de las obviedades de la verdad; únicamente se hará referencia a dos de ellas que, de una u otra manera, son compartidas por quienes pretenden conciliar el sentido común con la reflexión filosófica sobre esta noción. Estas dos intuiciones pueden ser caracterizadas de la siguiente manera:

(IC) La intuición de la correspondencia: una proposición (enunciado, oración, creencia, etc.) es verdadera cuando corresponde con los hechos; y

(IH) La intuición de la coherencia: preguntar por qué es verdadera una proposición (enunciado, oración, creencia, etc.) es preguntar cuáles son las razones que la sostienen.

Durante varios años estas intuiciones dieron lugar a dos tipos de teorías que permanentemente se presentaban en oposición. Para la gran mayoría de filósofos la mejor expresión de (IC) es el famoso pasaje de la Metafísica de Aristóteles: "Decir de lo que es que no es o de lo que no es que es, es falso, mientras que decir de lo que es que es y de lo que no es que no es, es verdadero" (1011b 25). De acuerdo con esta intuición, una proposición como la expresada por «el gato está sobre la alfombra» es verdadera si es un hecho que el gato está sobre la alfombra. Esta es quizá la intuición más fuerte con respecto a la verdad y, por esto, no es sorprendente que la mayor parte de estudiosos de esta noción se inclinen por una concepción correspondentista ${ }^{3}$.

Ahora bien, no todos los filósofos que aceptan (IC) se comprometen con una idea de representación pictórica entre el pensamiento (o el lenguaje) y el mundo. Hay defensores de esta intuición que «echan por la borda» esta noción de representación manteniendo la idea de correspondencia. Un ejemplo paradigmático es Austin (1950), para quien la correspondencia es una relación con-

2 Un notable ejemplo de esta divergencia lo constituyen Crispin Wright (1992), Michael Lynch (2004) y Pascal Engel (1998). Todos ellos afirman partir de (y en cierto sentido llegan a) las intuiciones de la verdad, pero cada uno está pensando en un conjunto de intuiciones distintas.

3 Meléndez (2002, p. 122) y Frápolli y Nicolás (1998, pp. 10-11) llaman la atención sobre la ambigüedad en el dictum mismo "verdad por correspondencia". Volveremos sobre esto un poco más adelante. 
vencional entre enunciados y estados de cosas (hechos o situaciones) ${ }^{4}$. La mayor parte de filósofos que defienden (IC), si bien no se comprometen necesariamente con una misma idea de representación, sostienen que esta intuición implica que la verdad es una especie de relación (pictórica, convencional, etc.) entre unas entidades que tienen la característica de «portar» la verdad (truth bearers) y otras entidades externas que tienen la característica de hacer verdaderas a las primeras (truth makers); a estas últimas se las conoce, generalmente, como hechos.

La principal característica de quienes favorecen (IC) sobre (IH) es que acercan (o ligan) la verdad a la metafísica. Si la verdad es una cierta relación entre un portador -llámese creencia, proposición, enunciado, etc.- y un hacedor de verdad -llámese hecho, cosa, estado de cosas-, se hace patente la necesidad de asumir la existencia de entidades externas para dar cuenta de manera satisfactoria de la noción de verdad. Como bien lo afirma Frápolli (2012), "[u]na vez es asumida la existencia de la clase apropiada de hechos, la verdad es definida de manera estándar como una correspondencia con los hechos de la clase en cuestión" (p.88). El defensor de (IC) generalmente está comprometido con la idea de que la verdad es una noción que permite vincular lenguaje y mundo.

Por otro lado, algunos filósofos que se encuentran más cercanos al pragmatismo -sobre todo al de James y Dewey-, sostienen que la verdad es «afirmabilidad garantizada», «afirmabilidad ideal» o «afirmabilidad al final de la investigación ${ }^{5}$. La razón que frecuentemente aducen para justificar estas posiciones es (IH) o una variante muy cercana. Richard Rorty (1994) ha puesto este elemento de la siguiente manera: "si tengo dudas concretas y específicas respecto de la verdad de una de mis creencias, solo puedo resolverlas preguntando si está adecuadamente justificada, buscando y sopesando razones complementarias en

4 "Un enunciado se dice que es verdadero cuando el estado de cosas histórico con el que está correlacionado por las convenciones demostrativas (aquel al que 'se refiere') es de un tipo con el de la oración usada al hacerlo está correlacionada por las convenciones descriptivas” (Austin, 1950, p. 122). Y, más adelante: "Aun cuando un lenguaje 'refleja' [rasgos descubiertos en el mundo] la verdad de los enunciados sigue siendo un asunto (...) que depende de que las palabras usadas sean las convencionalmente elegidas para situaciones del tipo al que pertenece la referida" (Austin, 1950, p. 125).

5 El pragmati(cis)mo de Peirce cae por fuera de esta caracterización general de las teorías pragmáticas. Peirce parece hacer (IC) e (IH) en la idea de final de la investigación: "La opinión destinada a que todos los que investiguen estén, por último, de acuerdo en ella es lo que significamos por verdad y el objeto representado por esa opinión es lo real" (Pierce, 1888, CP 5.407) 
pro y en contra" (p. 31). Para Rorty, preguntar si «el gato está sobre la alfombra» es verdadera, es preguntar si tenemos razones para sostener que «el gato está sobre la alfombra»; en otros términos, preguntar por la verdad de p es preguntar si p está justificada dentro de nuestro sistema de creencias.

La principal característica de quienes favorecen esta segunda intuición sobre la primera es que terminan acercando (o ligando) la verdad a la epistemología. Si bien es cierto que muchos de los defensores de esta intuición identifican verdad y justificación, esta no es una consecuencia que se siga necesariamente. De hecho, para evitar esta identificación y el relativismo al que -pese a lo que dice Rorty- inevitablemente conduce, algunos han optado por decir que la verdad tiene epistémicamente un grado más «alto» que la justificación, incluyéndola dentro de los conceptos epistemológicos ${ }^{6}$.

Como se puede observar, estas dos intuiciones dan lugar a dos tipos de teorías distintas sobre la verdad. Algunos piensan que estos están en una especie de contienda, es decir que si se acepta una, inmediatamente debe rechazarse la otra ${ }^{7}$. No obstante, basta con observar más de cerca para percatarse de que (IC) e (IH) parecen, más bien, estar evidenciando dos facetas distintas del tradicionalmente llamado «Problema de la verdad». Bertrand Russell fue consciente de esta distinción, al afirmar que no nos preguntamos cómo podemos conocer si una creencia es verdadera o falsa, sino qué significa la cuestión de si una creencia es verdadera o falsa (Russell, 1912, p. 105) ${ }^{8}$.

Frank Ramsey, unos años más tarde, también se dio cuenta de que bajo la expresión «problema de la verdad» realmente se esconden distintas preguntas:

6 En algunas concepciones se admiten grados de verdad siendo la certeza el grado más alto.

7 El mismo Rorty parece ser un ejemplo de esta actitud, para él, al aceptar (IH) (IC) pierde sentido. Lo único importante que puede decirse en este campo no versa sobre sobre la verdad misma, sino sobre las diversas prácticas de justificación.

8 En un texto posterior, Russell aclara todavía más esta posición: "La cuestión que tenemos que discutir es ecuál es la diferencia entre una creencia verdadera y una creencia falsa? Lo que equivale a preguntarse: ¿̨uál es la diferencia que realmente establece la verdad o falsedad de una creencia? No pregunto, en cambio, por lo que se denomina un criterio de verdad, es decir, por una cualidad, distinta de la verdad, que pertenece a lo que es verdadero y solo a ello. Esta distinción entre la naturaleza de la verdad y el criterio de verdad es importante y no siempre ha sido suficientemente destacada por los filósofos" (Russell, 1966, p. 216). 
¿Qué es la verdad? ¿Qué carácter es el que adscribimos a una opinión o a un enunciado cuando lo llamamos «verdadero»? Esta es nuestra primera cuestión, pero antes de intentar contestarla reflexionemos por un momento sobre lo que significa. Porque debemos distinguir una cuestión, «¿qué es la verdad?», de la cuestión bastante diferente «iqué es verdadero?» (...) No esperamos un medio infalible para distinguir verdad de falsedad, sino simplemente saber qué es lo que esta palabra «verdadero» significa. Es una palabra que todos entendemos, pero si tratamos de explicarla podemos fácilmente vernos envueltos, como muestra la historia de la filosofía, en un laberinto de confusión. (Ramsey, 1927, p. 294)

Russell y Ramsey no solo coinciden en distinguir estos problemas de la verdad, que de acuerdo con la tradición podemos nombrar como definicional y criteriológico, sino que ambos son enfáticos en mostrar su preocupación por el problema definicional, por saber qué significa que le atribuyamos verdad a una creencia, enunciado o proposición, antes que por descubrir un criterio para identificar creencias o proposiciones verdaderas.

El filósofo inglés, Peter Strawson, por otra parte, no solo aprueba la distinción entre estos dos problemas, sino que pone de manifiesto la prioridad del problema definicional sobre el criteriológico. Luego de hacer una crítica a la versión correspondentista de Austin, Strawson (1950) dice: "el daño ya está hecho al plantear la pregunta de ¿cuándo usamos la palabra «verdadero»? en lugar de ¿cómo usamos la palabra «verdadero»?” (p. 323 cursivas mías).

La preferencia que estos tres autores muestran por la pregunta ¿qué significa «verdadero»? no es casual: antes de que podamos dar respuesta a cuestiones criteriológicas sobre la verdad debemos ser capaces de decir cuál es el significado de esta noción. En otras palabras, antes de que podamos dar un criterio para distinguir si p es verdadera -incluso antes de que podamos saber si estamos en capacidad de dar un tal criterio- debemos ser capaces de mostrar qué queremos decir con «es verdadera $\gg$. Hay entonces que hacer frente a la segunda pregunta strawsoniana?

9 Huelga decir que, aunque los problemas definicional y criteriológico sean distintos, de aquí no se sigue que no puedan estar relacionados. De hecho, como se evidenciará más adelante, un análisis adecuado sobre el problema definicional arrojará luces sobre una faceta del problema criteriológico: la cuestión de cuáles son los criterios que nos permiten atribuirle verdad a una proposición, estrictamente hablando, cae por fuera del rango explicativo de una teoría de la verdad. 
De acuerdo con lo anterior, para una teoría de la verdad el problema definicional tiene prioridad sobre el problema criteriológico, es decir, antes de sacar cualquier conclusión acerca de las verdades o sobre la existencia de un método para llegar a ellas, debemos atender al significado de «es verdadero ${ }^{10}$. La pregunta que surge es ¿qué consecuencias tiene esta elección para el tratamiento de las intuiciones de la verdad mencionadas atrás? ¿Significa esto que tenemos que «echar por la borda» a (IH) y quedarnos solamente con (IC)? Aún más, ¿tenemos que aceptar toda la carga metafísica que generalmente es puesta por los correspondentistas en una teoría de la verdad? La respuesta a estas dos últimas preguntas es eminentemente negativa. Gran parte de esta respuesta se juega en la manera como entendemos las intuiciones de sentido común. El problema, a mi modo de ver, es que estas intuiciones tradicionalmente han sido «precargadas» filosóficamente y concebidas como el punto al cual debe llegar cualquier teoría de la verdad. La salida está en leerlas de la manera más inocente posible -sin ponerles de entrada ninguna carga metafísica, epistemológica, ética, etc.- y tomarlas como punto de referencia, esto es, como afirmaciones con las que no puede entrar en contradicción ninguna consecuencia de nuestra teoría de la verdad.

Como se evidenciará en lo que resta del escrito, es posible brindar una teoría que muestre de manera satisfactoria qué queremos decir con «es verdadero» -qué es lo que hacemos cuando cotidianamente usamos esta expresión- y que al mismo tiempo esté acorde con (IC) e (IH) sin comprometer a la noción de verdad con ninguna posición -específica o general- con respecto a la metafísica y a la epistemología. Para llevar a cabo esta labor, en primer lugar (sección 2), se analizará, de la mano de una versión reciente de la teoría prooracional de la verdad, la función que el predicado «es verdadero» cumple dentro de nuestro lenguaje natural. En segundo lugar (sección 3), se retomarán las dos intuiciones mencionadas al inicio del escrito con el fin de vislumbrar cómo puede analizarse su carácter intuitivo y su supuesta relación con la metafísica y la epistemología a la luz del estudio realizado.

10 Se asume aquí la conocida distinción hecha por Susan Haack (2005) entre la (noción de) verdad y la multiplicidad de proposiciones a las cuales la noción se aplica. 
2. Anáfora y afirmación: la función de «es verdadero» en nuestro lenguaje

EN LA BIBLIOGRAFÍA FILOSÓfiCA es recurrente encontrar a la verdad ligada a oraciones (Tarski, 1944; Field, 1994), enunciados (Austin, 1950), creencias (Russell, 1910; Ramsey, 1927), proposiciones (Wittgenstein, 1922), pensables (Hornsbi, 1997), entre otros. La pregunta que inevitablemente surge ante tal diversidad es: ¿a qué le atribuimos verdad? De acuerdo con Ramsey, "es evidente que la verdad y la falsedad de los enunciados depende de su significado, de lo que la gente quiere decir mediante ellos, los pensamientos y las opiniones que ellos transmitan” (Ramsey, 1927, p. 295). En efecto, en el uso común, no atribuimos verdad o falsedad a las oraciones por sí mismas, sino a lo que los hablantes dicen por medio de ellas. Un ejemplo paradigmático de esta atribución es: «lo que dijiste es verdadero». En este tipo de casos se puede observar que atribuimos verdad a lo que dice el otro en aquellas circunstancias específicas en las que hace una aserción; de hecho, para ser más exactos, atribuimos verdad al producto de su aserción ${ }^{11}$.

Por otra parte, es común también encontrar expresiones como «tu creencia de que el gato está sobre la alfombra es verdadera ». Ramsey se percata de que cuando le atribuimos verdad a una creencia, lo hacemos sobre lo que él llama su «referencia proposicional», el objeto sobre el cual versa la creencia. Así, "cuando dos hombres ambos creen que la tierra es plana decimos que tienen la misma creencia, aunque puedan creerlo en diferentes momentos, por diferentes razones, y con diferentes grados de convicción y usar diferentes lenguajes o sistemas de ideas" (Ramsey, 1927, 296). En este sentido, si decimos, por ejemplo, «tu creencia de que el gato está sobre la alfombra es verdadera» a lo que le atribuimos verdad es a «el gato está sobre la alfombra», a la referencia proposicional ramseyana, no a la creencia misma como estado mental ${ }^{12}$. Siguiendo la termino-

11 No interesan aquí las diversas formas en que puede aparecer gramaticalmente la verdad. Ciertamente esta noción puede aparecer como predicado - los ejemplos anteriores-, como sustantivo (p. ej., «dijiste la verdad»), como adverbio («esta persona habla verdaderamente»). Frápolli (2013, pp. 38ss) muestra que aunque gramaticalmente la verdad pueda aparecer en cualquiera de estas tres categorías, lógicamente está cumpliendo las mismas funciones. Funciones que trataremos en lo que sigue.

12 También podría decirse que atribuimos verdad a estados similares como suponer o saber. Podríamos decir, por ejemplo, «tu suposición de que el gato está sobre la alfombra es verdadera ». En este caso el análisis es análogo al de la creencia. 
logía de la filosofía del lenguaje contemporánea llamaremos a esto -a la referencia proposicional de la creencia y al producto de las aserciones- proposición.

Ahora bien, para lograr una comprensión satisfactoria de cómo funciona el predicado de verdad (o el discurso de verdad en general) dentro de nuestro lenguaje, no basta con determinar cuáles son las entidades a las cuales adscribimos verdad; es necesario ver cómo dicho predicado se comporta en relación con otros ítems lingüísticos, en relación con los contenidos, así como también en relación con los hablantes, esto es, qué hacen ellos -a qué se comprometencuando lo usan. En otras palabras, es necesario indagar cuál es el rol sintáctico, semántico y pragmático que nuestras adscripciones de verdad desempeñan dentro de nuestro lenguaje

La mayor parte de teorías de la verdad que se han planteado en los últimos años se concentra especialmente en alguno de estos tres roles. Así por ejemplo, la teoría del ascenso semántico de Quine (1990) y la teoría descitacional (disquotational) de Leeds (1978) y Field (1994) centran su atención principalmente en los aspectos sintácticos; por su parte, la teoría prooracional desarrollada por Grover (1992) y Williams (1976) -con antecedentes claros en Ramsey (1927) y Strawson (1950) - se enfoca sobre los aspectos semánticos; en tanto la teoría anafórica desarrollada en los últimos años por Brandom (1994) -con antecedentes claros también en Strawson (1950) - tiene como foco de atención los aspectos pragmáticos. En los últimos años, María José Frápolli (2013) ha articulado todas estas intuiciones, a su modo de ver parcialmente correctas, en una poderosa concepción que denomina teoría prooracional enriquecida (enriched prosentential account of truth). Esta teoría toma como eje central la explicación semántica que tradicionalmente ha hecho la teoría prooracional y la perfecciona con reflexiones acerca de las funciones sintácticas y pragmáticas que cumple el predicado de verdad. En lo que queda de esta sección presentaré a grandes rasgos esta teoría que constituye una excelente explicación del funcionamiento del discurso de verdad en nuestro lenguaje ${ }^{13}$.

13 La versión que presentaré a continuación es básicamente la presentada por Frápolli (2013). Expondré sus tesis fundamentales con mis palabras, usaré mis propios ejemplos y, donde lo crea necesario, la enriqueceré con algunas apreciaciones personales. 


\section{1}

De ACUERDo CON LA TEORÍA PROPORACIONAL, lo que gramaticalmente conocemos como el predicado «es verdadero» lógicamente trabaja en el lenguaje natural como un constructor de prooraciones complejas. Las prooraciones en los lenguajes naturales tienen un rol similar al de las variables en los lenguajes formales. Esta característica, como se verá más adelante, explica por qué atribuimos verdad de la misma manera a contenidos de diversa índole. Por ahora, es necesario detenernos un poco en la noción misma de prooración. Las prooraciones son parte de una clase de expresiones mucho más amplia que son las proformas. Dentro de esta clase, las expresiones más conocidas son los pronombres que, en términos generales, pueden ser caracterizados como expresiones que heredan su contenido anafóricamente de términos singulares o de actos referenciales directos. Aunque desde un punto de vista gramatical, la mayor parte de proformas aparezcan como pronombres, desde un punto de vista lógico además de estos también podemos encontrar proadverbios, proadjetivos y prooraciones, de acuerdo con la clase de expresión de la cual hereden su contenido.

No es necesario detenerse en cada una de las clases de proformas para entender el papel semántico que ellas desempeñan ${ }^{14}$. Sin embargo, puede ser útil referirse a la clase con la cual tenemos más familiaridad: los pronombres. En ellos podemos evidenciar con total claridad las tres funciones semánticas que realizan las proformas: (a) referencia directa, (b) referencia anafórica ${ }^{15}$ y (c) generalización. Consideremos los siguientes ejemplos para observar de qué modo estas proformas realizan cada una de tales funciones:

(1) Él es mi padre (señalando a alguien).

(2) Juan Manuel Santos se ha autoproclamado como el presidente de la paz, de seguro (él) está buscando la reelección.

(3) Si una selección de fútbol alcanza los 9 puntos en la primera fase del mundial, (ella) logrará la clasificación a la segunda ronda.

$14 \mathrm{Al}$ respecto ver: Frápolli, 2013, pp. 48ss.

15 La llamada «referencia catafórica» está incluida aquí dentro de la expresión «referencia anafórica». "Hablamos de anáfora cuando la proforma en cuestión remite a una expresión anterior de la que hereda su contenido. Hablamos de catáfora cuando la expresión a la que remite aparece después de la proforma. La diferencia es meramente retórica" (Frápolli, 2010, p. 181). 
En (1) el pronombre «él» está actuando como vehículo de referencia directa: el contenido que está adquiriendo proviene del gesto ostensivo que hace el hablante ${ }^{16}$. En (2) el pronombre «él» está actuando como vehículo de referencia anafórica, pues remite a un elemento que ha aparecido anteriormente del cual hereda su contenido. En este caso, el contenido heredado es «Juan Manuel Santos». En (3) el pronombre «ella» funciona como dispositivo de generalización. Quien profiera (3) no está haciendo una afirmación específica sobre un rasgo del mundo o sobre algún particular, sino que está afirmando que en cualquier caso que se cumpla lo que se enuncia en el antecedente, se cumplirá también lo que se dice en el consecuente. De suerte que en un lenguaje semiformalizado tenemos que:

$\forall \mathrm{x}$ ( $\mathrm{x}$ es una selección de fútbol clasificada al mundial \& $\mathrm{x}$ alcanza los 9 puntos en la primera fase del mundial $\rightarrow \mathrm{x}$ clasificará a la segunda ronda)

Consideremos ahora los siguientes ejemplos en los que la proforma desempeña el papel lógico de prooración:

(4) A - ¿Dijo algo mi padre antes de marcharse al trabajo? B -te dejó dicho esto (señalando una oración en un trozo de papel).

(5) El periodista Iván Mejía dijo que hay presiones para convocar a algunos jugadores a la selección Colombia y José Pekerman lo negó.

(6) Cuando el expresidente Uribe dice algo, Francisco Santos lo repite.

Es indudable que gramaticalmente «esto»y «lo» son pronombres. Sin embargo, en los ejemplos anteriores ellos no están por términos singulares, sino por expresiones oracionales completas; lógicamente hablando están cumpliendo la función de prooraciones. Aquí de nuevo pueden verse ejemplificadas las tres funciones semánticas señaladas anteriormente: en (4) la proforma actúa como vehículo de referencia directa, en (5) como referencia anafórica y en (6) como dispositivo de generalización, de manera que en un lenguaje semiformalizado se podría decir:

$\forall \mathrm{p}$ (si el expresidente Uribe dice $\mathrm{p} \rightarrow$ Francisco Santos dice $\mathrm{p}$ )

16 Como veremos más adelante, cuando examinemos el caso de las prooraciones complejas, para actuar como vehículo de referencia directa, no es necesario este gesto ostensivo. 
Es necesario reparar en que, a diferencia del caso en el que la proforma hereda un contenido singular, en este último ejemplo la variable cuantificada es una variable proposicional y no una variable nominal.

Ahora bien, con este trasfondo, consideremos los siguientes ejemplos de prooraciones complejas en los que se incluye el predicado gramatical «es verdadero»:

(7) La oración «el gato está sobre la alfombra» es verdadera.

(8) A -Mi padre ha dicho que en semana santa las ventas de pescado aumentan un 70\% B -Lo que él dijo es verdad.

(9) Daniel dijo que todos los enfermos, sin importar su condición social, deberían tener un trato digno por parte de las Entidades Promotoras de Salud y eso es verdad.

(10) La teoría de cuerdas es verdadera.

(11) Todo lo que dice el Papa es verdad.

En estos ejemplos aparecen prooraciones complejas en las que se evidencian las mismas funciones semánticas que en las demás clases de proformas. En (7), (8) y (9) se está adscribiendo verdad a un contenido proposicional distinto. (7) tiene la característica de que exhibe el contenido al cual se le está adscribiendo verdad, por esta razón se le conoce como adscripción de verdad exhibitiva. En este tipo de ejemplos la prooración está actuando como un vehículo de referencia directa. En esencia, todas las adscripciones exhibitivas singulares son instancias de la famosa convención-V de Tarski. Si el deflacionismo, tal como lo dicen Armour-Garb y Beall (2005, pp. 1-4), es definido como aquel conjunto de teorías que afirma que la convención- $V$ es conceptual y explicativamente fundamental, es decir, que no hay nada más que decir con respecto a la verdad sino lo que es implicado por la convención-V, entonces la acusación por parte de los llamados inflacionistas, de que al deflacionista se le queda algo por fuera, parece más que justificada.

Los ejemplos (8), (9) y (11) son casos de adscripciones de verdad ciegas y la explicación de su funcionamiento no se reduce en ningún sentido a la explicación de (7). Las adscripciones ciegas heredan su contenido anafóricamente. En (8) el contenido heredado es «en semana santa las ventas de pescado aumentan un $70 \%$ y en (9) es «todos los enfermos, sin importar su condición social deberían tener un trato digno por parte de las Entidades promotoras de salud». (8) y (9) constituyen ejemplos de afirmaciones totalmente distintas, una es empírica y la 
otra no, una tiene que ver con la manera como alguien piensa que deberían ser las cosas y la otra no. Sin embargo, pese a esa diferencia, en ambos casos la adscripción de verdad actúa de la misma manera: como una prooración que hereda anafóricamente un contenido proposicional para afirmarlo. La prooración, como le gusta decir a Frápolli, no tiene contenido en sí misma, pero sirve como vehículo para expresar cualquier contenido proposicional contextualmente preponderante (salient) (Frápolli, 2012, p. 92; 2013, p. 58). Esto no quiere decir que la verdad tenga significados distintos en contextos distintos, más bien que, teniendo en cuenta que el contenido no está determinado únicamente por los meros significados convencionales de las expresiones, en cada uno de los casos la verdad hereda contenidos distintos ${ }^{17}$.

(10) y (11) son casos que muestran que la verdad también sirve como dispositivo de generalización, especialmente en aquellos en que queremos hablar de grupos de proposiciones y no hacer meramente conjunciones entre contenidos individuales. (10) es un caso de adscripción exhibitiva general. En él lo que se está afirmando es que cualquier proposición que se siga de la teoría de cuerdas es verdadera. Así, en un lenguaje semiformalizado podemos decir que

$\forall \mathrm{p}$ (si p se sigue de la teoría de cuerdas (o de las tesis principales que definen a la teoría de cuerdas) $\rightarrow \mathrm{p}$ )

Por su parte, (11) es una adscripción ciega general. Quien profiere una oración como esta, está diciendo que cualquier cosa que diga el Papa es verdad. Las instancias que caen bajo estas clases de adscripciones no están determinadas por la adscripción misma como en el caso anterior. Una lectura semiformalizada de (10) sería:

$$
\forall \mathrm{p}(\text { si el Papa dice } \mathrm{p} \rightarrow \mathrm{p})
$$

Como ocurre en los casos anteriores de generalización, no hay aquí una afirmación de un contenido particular, sino una enunciación de una especie de regla para afirmar contenidos. Hay que tener en cuenta que las oraciones son proferidas por los hablantes en contextos específicos y el alcance de la referencia anafó-

17 Algo similar parece tener en mente Strawson cuando dice "tú dices de Juan «él está enfermo», yo digo a Juan «tú estás enfermo» y Juan dice «estoy enfermo». En todos los casos hacemos «el mismo enunciado» usando no solo oraciones diferentes, sino también oraciones con significados diferentes" (Strawson, 1950, p. 131 cursivas mías). 
rica o de los contenidos que se habilitan para ser afirmados se ve restringido por dichos contextos. Así, por ejemplo, si en un congreso de ética alguien profiere la oración «todo lo que dice el Papa es verdadero», parece estar refiriéndose a «todo lo que diga el Papa sobre x cosa (p. ej., respecto a algún tema ético específico) es verdadero», de suerte que no tendrá que retractarse ni entrar en conflictos con su afirmación si más adelante descubre que el Papa ha dicho «Tchaikovsky es el peor compositor de la historia» o algo por el estilo.

La función semántica del predicado «es verdadero», como se ha observado, pasa principalmente por los mecanismos de anáfora y generalización. Estos, a diferencia de lo que algunos piensan, no son menospreciables ni mucho menos eliminables del lenguaje. La intuición semántica que articula toda la teoría prooracional no la asemeja, como muchos han pensado, a la teoría de la redundancia ${ }^{18}$. "Sin las proformas, sin los mecanismos de anáfora y generalización, el poder expresivo de los lenguajes [lo que podemos decir mediante ellos,] se vería considerablemente reducido" (Frápolli, 2012, p. 91).

\section{2}

De aCUeRdo CON ALgunas Concepciones de la verdad, específicamente con aquellas que se denominan descitacionales, «es verdadero» no es un predicado en sentido estricto, sino que es un operador lógico que permite restablecer oracionalidad a expresiones singulares. Así, por ejemplo, en

(7) la oración «el gato está sobre la alfombra» es verdadera el rol del predicado de verdad es restablecer la función de oración a «el gato está sobre la alfombra». Detengámonos un momento aquí. En este ejemplo, tenemos básicamente dos dispositivos lingüísticos: unas comillas que tienen la función de convertir una expresión oracional en un término singular, con el objetivo de poder predicar o decir algo de ella, y «es verdadero» que restablece el estatus de oración a la expresión que está entrecomillada. Al primero se le conoce tradicionalmente como nominalizador y al segundo, como denominalizador

18 Eduardo Rabossi (1967, p. 86) presenta de manera bastante clara las principales tesis de la teoría de la redundancia: Sean $(\mathrm{s})$ «es verdad que la Pipa está sobre la mesa» y $(\mathrm{p})$ «la Pipa está sobre la mesa», el defensor de la redundancia sostiene que (1) cuando decimos (s), no afirmamos (s) sino (p). Expresar (s) no es afirmar nada acerca de (p) ni de otras cosas, sino que es meramente afirmar (p); y (2) decir ( $\mathrm{s}$ no es hacer nada más o no es hacer nada más importante que afirmar ( $\mathrm{p}$ ). 
(Horwich, 1998, p. 5). Esta función no es para nada desdeñable, pues lo que está haciendo la noción de verdad aquí es expresando una proposición que anteriormente había sido designada por medio de las comillas ${ }^{19}$. Esta diferencia se puede ver claramente si comparamos (7) con

$\left(7^{*}\right)$ la oración «el gato está sobre la alfombra».

Si un hablante profiere algo como $\left(7^{*}\right)$ no está afirmando estrictamente que el gato está sobre la alfombra, esto es, no está realizando estrictamente una aserción, sino que está designando una proposición. De hecho, $\left(7^{*}\right)$ es una oración gramaticalmente mal formada. "La conversión de un término singular en una oración adapta una herramienta referencial $\left[7^{*}\right]$ convirtiéndola en un vehículo de aserción [7]" (Frápolli, 2013, p. 24). Este tipo de función sintáctica es la que en términos generales desempeña cualquier operador de orden superior ${ }^{20}$.

Hay casos en los que la verdad no aparece como un predicado, sino como un operador: «es verdadero que». En esencia no hay diferencia alguna entre expresar una proposición con el predicado o con el operador de verdad. Así, por ejemplo,

$\left(7^{* *}\right)$ es verdad que el gato está sobre de la alfombra, está expresando esencialmente lo mismo que (7). En este caso, la expresión también consta de un nominalizador: la cláusula «que», y un denominalizador: «es verdad».

Los casos de adscripciones de verdad exhibitivas como $(7)$ y $\left(7^{* *}\right)$ parecen alimentar la tesis de la redundancia, pues podría decirse que en estos dos ejemplos no se expresa ni más ni menos que lo mismo que es expresado por «el gato está sobre la alfombra». Esta ilusión de la redundancia es alimentada aún más por la intuición semántica, observada en 2.1, según la cual la verdad no tiene contenido por sí misma. Si a esta intuición le sumamos la tendencia eliminativista que suele acompañar a algunos análisis lógico-semánticos de la verdad, no es

19 La diferencia entre designar una proposición y expresar una proposición es puesta de manifiesto por William y Martha Kneale (1982, 584-586).

20 Esta explicación no funciona si uno acepta la interpretación tradicional (tarskiana) de las comillas como bloque lógico. En su lugar se puede ofrecer una explicación de las comillas como demostrativos, es decir, como expresiones que sirven para señalar palabras y conjuntos de palabras (Frápolli, 1998, pp. 103-104). En este caso, las comillas reemplazan el gesto ostensivo al que se aludió en 2.1 para explicar la función semántica de referencia directa de los pronombres. 
sorprendente la conclusión de que el concepto de verdad es eliminable, pues todo lo que puede ser expresado con él puede ser expresado de la misma manera sin él. No obstante, esta ilusión redundantista empieza a desvanecerse tan pronto tratamos las adscripciones ciegas, pues en ellas el contenido de la adscripción no puede ser recobrado sin los mecanismos anafóricos propios de las proformas.

En las adscripciones ciegas el predicado (u operador) desempeña la misma función sintáctica que en las exhibitivas: restablecer la oracionalidad a una expresión convirtiéndola en vehículo de aserción. Así por ejemplo, en la adscripción de verdad presente en (8) A -Mi padre ha dicho que en semana santa las ventas de pescado aumentan un $70 \% \mathrm{~B}$-lo que dijo mi padre es verdadero, B está designando una proposición, en este caso por medio de una descripción definida, y luego expresándola. El sujeto gramatical «lo que dijo mi padre» hereda anafóricamente el contenido proposicional «en semana santa las ventas de pescado aumentan un 70\%» y el predicado gramatical «es verdadero» está expresando dicho contenido. En este sentido, B no está simplemente haciendo referencia a lo que dijo su padre, sino que está expresándolo, es decir, está afirmando que en semana santa las ventas de pescado aumentan un $70 \%$. No hay diferencia alguna cuando la verdad aparece como operador. En el siguiente caso, B está expresando exactamente la misma proposición que en (8):

( $\left.8^{*}\right)$ B -Es verdad lo que dijo mi padre (en el mismo contexto que (8)).

$\mathrm{Al}$ igual que ocurre con la función semántica, la verdad cumple su función sintáctica independientemente del tipo de contenido al que restablece la oracionalidad. Funciona igual con proposiciones empíricas, éticas («es verdad que los hombres y las mujeres tienen igualdad de derechos»), matemáticas («que $2+2=4$ es verdadero»), etc. Esto no debe llevarnos a pensar que la verdad es ambigua, pues en términos generales está cumpliendo la misma función semántica y sintáctica, aunque aplicada a diferentes contenidos ${ }^{21}$.

21 Dicho sea de paso, esta característica permitiría explicar una de las obviedades de la verdad que, según Michael Lynch (2004), se presenta como la más complicada para una explicación filosófica de la verdad: la verdad es una y muchas. 


\section{3}

Si BIEN, SE HA HECHO ÉNFASIS en mostrar que tanto sintáctica como semánticamente el predicado (u operador) de verdad no es redundante pues cumple funciones específicas que no son eliminables, el teórico de la redundancia podría decir que su intuición de que la verdad no agrega nada a la proposición a la cual se adscribe sigue incólume y, por tanto, la teoría prooracional no es más que una teoría de la redundancia sofisticada. Esta posible acusación tiene una intuición correcta, pero su conclusión es cuando menos apresurada, pues se basa en un supuesto estrecho y desactualizado acerca del significado. La intuición correcta es que la verdad no le añade nada al contenido de la proposición a la cual es adscrita; como mostró nuestro análisis semántico, las adscripciones de verdad por sí solas son desprovistas de contenido. Las adscripciones de verdad desprovistas de contexto carecen de contenido de la misma manera que lo hace una variable proposicional no interpretada en el lenguaje lógico. El supuesto erróneo es que todas las expresiones significan de la misma manera: de manera referencial y/o descriptiva. Este supuesto no es más que lo que Austin denunció como falacia descriptivista. Según esto, dado que «es verdadero» no tiene capacidad referencial ni descriptiva, no tiene significado. Este supuesto desconoce que gran parte de las expresiones de nuestro lenguaje, especialmente aquellas que son operadores de orden superior, tienen significado sin tener capacidad referencial ni descriptiva.

De acuerdo con la teoría prooracional de Frápolli (2013, pp. 71ss), la verdad tiene un significado expresivo en la medida en que: (a) es veritativo-condicionalmente irrelevante, esto es, no afecta las condiciones de verdad de la proposición a la cual es adscrita, y (b) explicita algunos rasgos característicos del acto en progreso, es decir, al usar una adscripción de verdad el hablante muestra que está involucrado en un acto de aserción y hace explícitos los compromisos que adquiere al ejecutar dicho acto. "Al afirmar un contenido un hablante se compromete con las consecuencias de su aserción; con las consecuencias que se siguen del contenido afirmado y con las consecuencias que se siguen de haberlo afirmado" (Frápolli, 2009, pp. 76-77). Estos son los compromisos que se explicitan al adscribir verdad a un contenido. Así, por ejemplo, en (8) cuando B dice «lo que dijo mi padre es verdad» no solo se está refiriendo al contenido expresado por la oración «En semana santa las ventas de pescado aumentan un 70\%» sino que 
además está expresando sus compromisos inferenciales con dicho contenido; en otras palabras, está mostrando su capacidad para dar razones que apoyen ese contenido. De acuerdo con la terminología de Brandom (2009), al atribuir verdad a un contenido estamos (a) mostrando que puede ser usado como premisa en juegos inferenciales y (b) exhibiendo nuestro compromiso de dar razones que apoyen ese contenido. Cuáles sean esas razones dependerá del tipo de contenido afirmado y del contexto en el cual se esté afirmando. Esta función pragmática muestra un rasgo esencial que será retomado en la siguiente sección: la adscripción de verdad ocurre una vez los contenidos ya han sido aceptados, esto es, una vez los contenidos ya tienen el estatus epistémico de conocimiento; estrictamente hablando, las adscripciones de verdad no producen ni causan el estatus epistémico de conocimiento aceptado. Este es uno de los puntos en el que Frápolli más ha enfatizado (2007, p. 112; 2012, p. 95; 2013, p. 128).

Ahora bien, asumir la división clásica entre sintaxis, semántica y pragmática para explicar la manera como las adscripciones de verdad funcionan en nuestro lenguaje no implica necesariamente que estas tres funciones se presenten de manera separada en el uso real. El predicado gramatical «es verdadero» no podría funcionar correctamente sin la herencia anafórica de contenido y, a su vez, no podríamos llevar a cabo la función pragmática de evidenciar los compromisos si sintácticamente no se produce la conversión de aquellas designaciones de proposiciones en vehículos de aserción. Cotidianamente atribuimos verdad a los contenidos de manera correcta y sin mayores dificultades, tal vez esto sea lo que nos lleve a pensar que el funcionamiento de la verdad dentro de nuestro lenguaje es una trivialidad. Aún si aceptamos que es una trivialidad, esto no implica que la explicación de por qué lo es sea también trivial.

SON VARIAS LAS INTUICIONES de sentido común que se tienen con respecto a la verdad. Además de las dos citadas podríamos mencionar «la ciencia busca la verdad», «es mejor creer lo verdadero que lo falso», «la verdad es objetiva», entre otras. (IC) e (IH) son importantes en la medida en que conforman el núcleo de lo que podríamos denominar el significado presistemático de la verdad, esto es, el significado que tienen en mente cualquier hablante competente que 
usa, sin ningún tipo de problemas, esta noción. La concordancia de una teoría de la verdad con este significado, y por lo tanto con las dos intuiciones mencionadas, no es solo una cuestión de sofisticación o de moda filosófica, sino que es una exigencia palmaria si queremos que nuestras reflexiones filosóficas en el campo de la verdad den cuenta del uso efectivo que hacemos de esta noción en la vida cotidiana. Una teoría de la verdad que no arroje luz sobre los usos cotidianos de esta noción será de muy poco valor.

\section{1}

(IC) EXPRESA LA INTUICIÓN que normalmente tenemos de que una proposición es verdadera cuando lo que se dice mediante ella efectivamente ocurre. Cuando un hablante ordinario expresa esta intuición, no está preocupado por cuáles son los constituyentes últimos del mundo, es decir, para él es indiferente si expresa (IC) por medio de los términos «hechos»o «estado de cosas»o «realidad». En términos generales, y sin entrar en una sofisticación metafísica, lo que le interesa a un hablante, sobre todo cuando habla con respecto a algo que ocurre o ha ocurrido en el mundo, es decir que una proposición es verdadera cuando lo que dice es un hecho. Así, podríamos expresar esta intuición de la siguiente manera:

(IC*) Es verdad que p si y solo si es un hecho que $\mathrm{p}^{22}$.

De acuerdo con esta intuición, podemos decir que:

(12) Es verdad que el gato está sobre la alfombra si y solo si es un hecho que el gato está sobre la alfombra.

(13) Es verdad que las ventas de pescado aumentan un $70 \%$ si y solo si es un hecho que las ventas de pescado aumentan un $70 \%$

(14) Es verdad que Viviana vino a Bogotá si y solo es un hecho que Viviana vino Bogotá.

Estos tres casos, por tratarse de proposiciones acerca del mundo, alimentan la idea filosófica de que la verdad es una noción que permite unir mundo y lenguaje o, para ponerlo en términos de Grover (1990), una expresión de conexión lenguaje-mundo (language-world connection) y, en este sentido, aparentemente

22 De acuerdo con lo dicho en 2.1 (supra), esta versión es igual a:

$\left(\mathrm{IC}^{* *}\right)$ «p» es verdadera si y solo si es un hecho que p. 
comprometen a la verdad con una metafísica específica ${ }^{23}$. No obstante, este supuesto compromiso empieza a desvanecerse una vez se hace análisis del operador «es un hecho que».

El operador «es un hecho que», al igual que el predicado gramatical «es un hecho», hace parte del discurso de la verdad, esto es, actúa de la misma manera que el operador y/o el predicado de verdad. En su ya clásico artículo "Truth", Strawson enumera varias expresiones que funcionan de la misma manera que el operador de verdad: «es un hecho que», «es indiscutible que», «está establecido fuera de duda que», entre otros (Strawson, 1950, p. 323). Si anteponemos cualquiera de estos operadores a un contenido proposicional, el resultado será básicamente el mismo: no se modificarán las condiciones de verdad del contenido, sino que se estará afirmándolo y exhibiendo los compromisos adquiridos tras su afirmación. Así,

(15) Es un hecho que el gato está sobre la alfombra,

consta de un nominalizador: la cláusula «que», y un denominalizador: «es un hecho». En este caso, al igual que ocurre con el operador de verdad la labor sintáctica de estas dos expresiones se cancela y, en consecuencia, la oración entera es un vehículo para afirmar que el gato está sobre la alfombra.

Si este análisis es correcto, la verdad de (IC) es analítica, lo cual explica su carácter intuitivo. Es interesante notar que para dar cuenta de (IC) no fue necesario postular entidades externas de cierto tipo que hagan verdaderas a nuestras proposiciones. La verdad, como ya se dijo, no es una expresión de conexión lenguaje-mundo y, por tanto, su significado puede ser caracterizado sin necesidad de hablar de la estructura del mundo. Naturalmente, de este análisis no se sigue que no haya realmente una conexión lenguaje-mundo, ni mucho menos que no sea importante la pregunta por tal conexión.

Es posible que el defensor correspondentista de (IC) replique afirmando que lo que el hablante común y corriente asocia con esta intuición va mucho más allá de su mero carácter analítico y que realmente en nuestro discurso de la verdad hay una referencia al mundo. Después de todo, podría decir el objetor, cuando

23 Puede ser una metafísica de situaciones (Austin, 1950), de hechos o estados de cosas (Russell, 1910 y 1966; Wittgenstein, 1922) o, de cosas. 
decimos que una proposición como la expresada por «el gato está sobre la alfombra» es verdadera lo que estamos queriendo decir es que en el mundo (sin importar si se trata de un hecho, un estado de cosas, una situación, etc.) está ocurriendo algo específico (p. ej., que hay algo que comúnmente llamamos un gato que está encima de algo que comúnmente llamamos una alfombra). Esta manera de entender la noción de verdad surge básicamente porque se la adscribe únicamente al uso descriptivista del lenguaje. Si se piensa que la verdad ocurre solamente en casos similares a (12)-(14), donde lo que se quiere afirmar es algo acerca del mundo, no es extraña la conclusión del correspondentista. Sin embargo, cotidianamente no solo usamos la noción de verdad cuando hablamos acerca de la realidad empírica. Así, por ejemplo:

(16) Es verdad que hay un único número entero positivo menor que todos los demás.

(17) Es verdad que tanto los hombres como las mujeres tienen los mismos derechos.

(18) Es verdad que todos los enfermos deberían tener un trato digno por parte de las Entidades Promotoras de Salud.

(19) Es verdad que debemos tener un trato respetuoso con los adultos mayores.

No hay nada extraño o erróneo en estos ejemplos; pueden ser afirmados y entendidos por cualquier hablante competente. Cotidianamente adscribimos verdad a contenidos que no son empíricos sin comprometernos por esto con la existencia de hechos éticos, matemáticos ni mucho menos con una multiplicación innecesaria de la realidad. Ante los ejemplos (16)-(19) el correspondentista tiene, por lo menos, dos opciones: (A) negar que sean usos legítimos de la noción de verdad o (B) afirmar que lo son y explicar de qué modo serían verdaderos los contenidos expresados en ellos $^{24}$. El problema con la primera opción es que con-

24 Evidentemente, no todos los correspondentistas tienen la misma interpretación de (16)-(19). Así, por ejemplo, Wittgenstein piensa que estas no son proposiciones legítimas y, como tal, su función no es decir sino mostrar. Austin, por su parte, tampoco acepta que enunciados como los de la matemática o los de la ética sean descripciones en sentido estricto, es decir, no funcionan de la misma manera que los enunciados en los cuales estamos describiendo una situación. Alguien que se inscriba dentro del emotivismo tendrá a su vez una explicación distinta del significado de las expresiones éticas. De cualquier forma, lo que se quiere subrayar aquí es que el correspondentista que acepte esta opción debe decir que (16)-(19) no corresponden a usos legítimos de la verdad, en el mejor de los casos, son usos metafóricos en los que la noción de verdad no funciona exactamente de la misma manera. 
duce al correspondentista - por lo menos al que defiende el carácter intuitivo de (IC) - a una especie de inconsistencia: por un lado se apoya en el uso que cotidianamente hacen los hablantes de la noción de verdad para sustentar su idea de que la verdad es una expresión de conexión lenguaje-mundo, pero, por otro lado, propone que el hablante cotidiano utiliza la noción de verdad de manera equivo$\operatorname{cada}^{25}$. De elegir la segunda opción, el correspondentista tendría que explicar de qué manera son verdaderos los contenidos presentes en (16)-(19), algo que probablemente lo conduciría a afirmar que las proposiciones expresadas en estos ejemplos corresponden con una realidad de distinto tipo. El problema con esta segunda opción radica en la multiplicación un tanto injustificada del mundo. En efecto, estas no son las únicas dos opciones que le quedan al correspondentista, probablemente encuentre alguna artimaña teórica para acomodar su teoría, pero, en todo caso, parece claro que la carga de la prueba está de su lado.

De acuerdo con la concepción prooracional de la verdad, en todos los casos que hemos analizado en esta sección (12)-(19), la noción de verdad está desempeñando exactamente el mismo papel (cumple la misma función sintáctica, semántica y pragmática) siendo adscrita a distintos contenidos. Parafraseando el famoso pasaje de Aristóteles, decir que p y p o decir que no-p y no-p es lo verdadero. Para explicar esta trivialidad, sin embargo, no hay que presuponer la naturaleza (empírica) de p.

Nelida Gentile (2013) afirma que la concepción prooracional debe presuponer una visión correspondentista de la verdad so pena de incurrir en una contradicción pragmática. El argumento de Gentile es que si la concepción prooracional -y, a juzgar por el argumento, cualquier teoría de la verdad- pretende dar cuenta de la manera como cotidianamente los hablantes usan la noción de verdad, entonces parece infiltrarse, implícitamente y sin quererlo, una noción correspondentista de la verdad; una teoría de la verdad, de acuerdo con Gentile, en tanto explicativa del funcionamiento del discurso de la verdad se corresponde con la realidad objetiva constituida por los hechos lingüísticos generados por los hablantes (Gentile, 2013, pp. 6-8). Esta objeción, no obstante, es circular, pues fun-

25 Así mismo, se vería enfrentado al llamado problema Frege-Geach, esto es, tendría que explicar por qué las proposiciones, pongamos por caso, éticas pueden en algunas inferencias servir como funciones de verdad. Al respecto ver: Schroeder, 2008. 
ciona únicamente si se asume que el objetivo de las teorías es reflejar fielmente la estructura del hecho que pretenden explicar, esto es, si se asume de entrada que la tarea de una teoría es corresponder con la realidad. Afirmar que la concepción prooracional es una teoría verdadera acerca de la verdad (o de su significado) es, de acuerdo con lo que ella misma sostiene, expresar que para toda proposición p, si p se sigue de la teoría prooracional de la verdad, entonces se está dispuesto a afirmar y defender (dar razones a favor de) que $\mathrm{p}$.

\section{2}

¿CUÁNDO Y POR QUÉ ADSCRIBIMOS VERDAD a un contenido? (IH) expresa la respuesta que desde nuestro sentido común damos a esta pregunta. De acuerdo con esta intuición, adscribimos la verdad a un contenido una vez tenemos las razones suficientes a su favor. Así, por ejemplo, en (8) suponemos que B adscribe verdad al contenido «en semana santa las ventas de pescado aumentan un $70 \%$ » porque, entre otras cosas, él tiene razones para afirmar dicho contenido. Si alguien le pregunta por qué, él debe dar razones a su favor; después de todo, como ya se dijo en 2.3, ese es uno de los compromisos que la verdad hace explícitos. Esta conexión tan cercana entre verdad y razones es, principalmente, lo que ha llevado a algunos filósofos a concebir la verdad como un concepto epistemológico. Sin embargo, como se mostrará en lo que sigue, esta conexión no es más que una herencia de la conexión entre aserción y razones; por tanto, de ella no se sigue que la verdad sea un concepto epistemológico ni que, a fortiori, esté ligado con una teoría epistemológica o una definición de conocimiento específicas.

De acuerdo con la concepción esbozada en la sección anterior, la adscripción de verdad actúa una vez los contenidos ya han sido afirmados, ya sea por el propio hablante o por uno distinto y en ese mismo contexto o en uno distinto. La adscripción de verdad opera una vez se ha puesto de manifiesto un contenido proposicional por medio de un acto de aserción. Esto ocurre así tanto en las adscripciones exhibitivas, donde se señala el contenido proposicional (7), como en las ciegas, donde el contenido se hereda de manera anafórica (8) y (9). Estas adscripciones actúan de la misma manera, independientemente del tipo de contenido que haya sido afirmado en el acto anterior. "Una vez el acto de aserción es exitoso, yo mismo o un hablante distinto puede aprobar (endorse) su contenido en el mismo contexto o en uno diferente por medio de una adscripción de verdad 
que tiene el contenido del acto de aserción como su propio contenido" (Frápolli, 2013, p. 130). En este sentido, la adscripción de verdad a un contenido se da una vez este ya ha pasado los filtros epistemológicos propios para ser afirmado, pero en sentido estricto, la verdad no produce estatus epistemológico alguno en el contenido al cual es adscrita. Así, por ejemplo:

(8) A -Mi padre ha dicho que en semana santa las ventas de pescado aumen$\tan$ un $70 \% \mathrm{~B}-$-lo que dijo mi padre es verdadero.

En este caso, como se ha dicho, B adscribe verdad al contenido afirmado por A. Para adscribir verdad a este contenido, $B$ no debe añadir razones adicionales a las que tendría para afirmarlo. Al hacer la adscripción, B está indirectamente afirmando y exhibiendo, entre otros, su compromiso de dar razones a su favor, pero estas razones no son ni más ni menos que las mismas razones que tiene para afirmarlo. Lo que muestra este hecho es que los criterios de afirmación de un contenido son los mismos criterios de verdad; en otras palabras, las razones que tengo para afirmar que en semana santa las ventas de pescado aumentan un $70 \%$, son las mismas razones que tengo para adscribirle verdad a «en semana santa las ventas de pescado aumentan un $70 \% »$. Naturalmente, esto no significa que verdad y justificación tengan la misma naturaleza. La verdad se encuentra en un nivel (lógicamente) distinto de aquel en el que justificamos un contenido. El nivel de la justificación es el nivel de las razones que se tienen para afirmar un determinado contenido proposicional, mientras que el nivel de la verdad surge una vez el contenido ha sido afirmado ${ }^{26}$. Lo que muestra este análisis es que, como lo sugiere Eduardo Fermandois (2001), verdad y justificación tienen una intrínseca relación y, a la vez, una imborrable diferencia.

Los filtros epistémicos que debe superar un contenido para ser afirmado de manera exitosa dependen del contenido y del contexto en el cual es afirmado. Los contenidos expresados en (8) y (16) son distintos y las razones por las cuales estamos habilitados para afirmarlos también lo son. Claramente debe hacerse un estudio acerca de los filtros epistémicos adecuados en distintos contextos; esta es una tarea propia de la epistemología y no de una teoría de la verdad.

26 Estas reflexiones conducen a una conclusión claramente antirortiana: asumir $(\mathrm{IH})$ no conduce a la identificación de verdad y justificación ni, mucho menos, a la eliminación de esta segunda por medio de argumentos neopragmatistas. 
Ahora bien, es posible que algún objetor afirme que la verdad es una noción eminentemente epistemológica debido a que se encuentra inmersa en nuestra (clásica) definición de conocimiento. Bien es sabido que para que p sea considerada como conocimiento, al menos desde la visión clásica, debe ser una creencia verdadera justificada. En este sentido, proseguiría el objetor, la verdad es constituyente esencial del conocimiento y, como tal, es una noción que pertenece a la epistemología. De acuerdo a como se encuentra formulada esta objeción, tenemos básicamente dos caminos, ambos problemáticos: (1) aceptar la definición tradicional de conocimiento y con ello, según el objetor, aceptar que la verdad es, en últimas, un concepto epistemológico; o (2) aceptar que el análisis lógico-lingüístico de la verdad tiene como consecuencia el rechazo de la visión clásica de conocimiento, en cuyo caso tendríamos que admitir que la tal neutralidad epistemológica de la verdad no existe.

El problema de esta objeción, sin embargo, radica justamente en la manera como se encuentra formulada. Decir que la verdad no es un concepto epistemológico y que es neutral con respecto a la epistemología, evidentemente implica que la elucidación de su significado es independiente de la concepción de conocimiento que tengamos. Bien podríamos favorecer una noción clásica o una no clásica de conocimiento y el significado de la verdad no tiene por qué cambiar. Afirmar que el conocimiento es creencia verdadera justificada es compatible con el análisis lógico-lingüístico de la verdad. Cuando atribuyo a alguien el conocimiento de que $\mathrm{p}$-dentro de la visión clásica de conocimiento- estoy: (A) atribuyéndole la creencia de que $\mathrm{p},(\mathrm{B})$ aceptando que está habilitado para afirmar $\mathrm{p}$, esto es, que puede justificar p, y (C) debo aprobar y afirmar (endorse) p, esta última es la que corresponde a la condición de verdad del conocimiento (Brandom, 2009, pp. 157-158). Así, por ejemplo si digo

(20) B sabe que la Universidad de los Andes tiene 30 edificios,

Estoy $\neq(\mathrm{A})$ atribuyendo a $\mathrm{B}$ la creencia de que la Universidad de los Andes tiene 30 edificios, (B) aceptando que está habilitado para afirmar que la Universidad de los Andes tiene 30 edificios, es decir, que está en capacidad de dar razones a favor de ese contenido y (C) aprobando y afirmando (endorse) la creencia de que la Universidad de los Andes tiene 30 edificios, esto es, hago explícito que tam- 
bién estoy dispuesto a afirmar dicho contenido ${ }^{27}$. En este sentido, favorecer la noción clásica de conocimiento no implica necesariamente una noción de verdad distinta a la esbozada en la sección anterior: decir que el conocimiento es una creencia justificada que, además, es verdadera, solo significa que uno también está dispuesto a afirmar el contenido de dicha creencia.

Antes de terminar quizá sea pertinente, a manera de conclusión, resumir lo que se ha defendido. En primer lugar, a partir de un análisis lógico-lingüístico se ha mostrado que la verdad permite ejecutar varias funciones complejas dentro de nuestro lenguaje. Sintácticamente el predicado (u operador) de verdad restablece el estatus de oración a expresiones singulares con contenido oracional, lo que permite que las adscripciones de verdad sirvan como medios para la aserción de contenidos completos. Semánticamente, tales adscripciones pertenecen a la clase de las proformas y, como tal, cumplen una función triple: (A) referencia directa, (B) referencia anafórica y (C) generalización. En nuestro lenguaje natural las adscripciones de verdad funcionan de manera similar a como funcionan las variables proposicionales en los lenguajes formales, ellas pueden heredar y expresar cualquier contenido que haya sido afirmado en un acto asertivo exitoso. Pragmáticamente, al adscribir verdad se explicitan los contenidos adquiridos por parte del hablante a la hora de afirmar un contenido. La separación de estas tres funciones, según se ha evidenciado, solo es posible para fines teóricos; en la práctica cuando un hablante adscribe verdad lleva a cabo estas funciones de manera indistinta. La elucidación de estas funciones ha evidenciado que para hacer un análisis de la verdad no es necesario aludir a la naturaleza del mundo en el que habitamos ni a la naturaleza de nuestras capacidades epistémicas para conocer dicho mundo; uno puede mantener cualquier teoría en epistemología o en metafísica y esto no tiene por qué afectar la concepción que tenemos de la verdad. Del mismo modo, se ha mostrado que la concepción prooracional permite explicar el carácter intuitivo de dos de nuestras más poderosas intuiciones de sentido común

27 Atribuir conocimiento a alguien sobre un contenido específico algunas veces, pero no siempre, significa que estoy habilitado para afirmar tal contenido. Yo puedo reconocer que B sabe que $\mathrm{p}$ (siendo p un contenido complejo de alguna ciencia) y en ese caso yo no puedo dar razones a su favor. Si, como lo sugieren los epistemólogos sociales contemporáneos no-reduccionistas (y antes que ellos Reid y Austin), aceptamos el testimonio como fuente de justificación epistémica, esta cuestión podría cambiar. Esta es, sin embargo, una discusión epistemológica que desborda el presente trabajo. 
acerca de la verdad, (IC) e (IH), sin inscribir esta noción dentro de una teoría epistemológica o metafísica concretas.

\section{Referencias}

Amour-Garb, B. \& Beall, J.C. (2004). Deflationism: the Basics. B. Amour-Garb \& J.C. Beall. (Eds.), Deflationary Truth (pp. 1-30). Chicago: Open Court. Aristóteles. (1982). Metafísica. (Trad. V. García Yebra). Madrid: Editorial Gredos. Austin, J. (1950). Verdad. (Trad. A. García). M.J. Frápolli \& J.A. Nicolás. (Eds.), Teorias contemporáneas de la verdad (pp. 117-134). Madrid: Tecnos.

Brandom, R. (2009). Reason in Philosophy. Cambridge, Mass.: Harvard University Press.

Brandom, R. (1994). Making it Explicit. Cambridge, Mass.: Harvard University Press.

Engel, P. (1998). La verdad. (Trad. Heber Cardoso). Buenos Aires: Amorrortu. Fermandois, E. (2001). Verdad y Justificación. Ideas y valores, 50(117), pp. 55-78.

Field, H. (1994). Deflationists Views Meaning and Content. Mind, 103, pp. 249-285.

Frápolli, M.J. (2013). The Nature of Truth. An Update Account of Truth Ascriptions. Dordrecht: Springer.

Frápolli, M.J. (2012). The Neutrality of Truth in the Debate Realism Vs. Antirealism. S. Rahman, G. Primeiro \& M. Marion. (Eds.), The Realism-Antirealism Debate in the Age of Alternative Logics (pp. 85-100). Dordrecht: Springer.

Frápolli, M.J. (2010). It Takes Two to Make a Truth. Revista Portuguesa de Filosofia, 66, 173-184.

Frápolli, M.J. (2009). The Relativism of Truth vs. The Dogmatism about Truths. A false Dichotomy. Teorema, 28(3), pp. 65-79.

Frápolli, M.J. (2007). Is Truth an Epistemic Value? A. Nepomuceno (et. al.). (Eds.), Lógica, Filosofía del Lenguaje y de la Lógica (pp. 105-117). Sevilla: Mergablum.

Frápolli, M.J. (1998). La lógica de "es verdadero". M.J. Frápolli \& J.A. Nicolás. (Eds.), Verdad y experiencia (pp. 91-108). Granada: Comares. 
Frápolli, M.J. \& Nicolás, J.A. (1998). Introducción: teorías actuales de la verdad. M.J. Frápolli \& J.A. Nicolás. (Eds.), Verdad y experiencia (pp. 1-41). Granada: Comares.

Gentile, N. (2013). Sobre la neutralidad de la verdad en el debate realismo-antirealism. Ponencia presentada en el Congreso de la Sociedad Interamericana de Filosofía, Salvador de Bahía, Brasil. Recuperado el 12 de enero de 2014: http://www.sif2013.org/encontros/17/trabalhos/344\%20-\%20es\%20-\%20 Gentile_Sobre\%20la\%20neutralidad\%20de\%20la\%20verdad.pdf

Grover, D. (1992). A Prosentential Theory of Truth. Princeton: Princeton University Press.

Grover, D. (1990). Truth and Language-World Connections. The Journal of Philosophy, 87(12), pp. 671-687.

Horwich, P. (1998). Truth. Oxford: Oxford University Press.

Haack, S. (2005). The Unity of Truth and the Plurality of Truths. Principia, 9, pp. $87-100$.

Hornsby, J. (1997). La verdad: teoría de la identidad. (Trad. M.J. Frápolli). M.J. Frápolli \& J.A. Nicolás. (Eds.), Teorías contemporáneas de la verdad (pp. 347-372). Madrid: Tecnos.

Kneale, W. \& Kneale, M. (1982). The Development of Logic. Oxford: Oxford University Press.

Leeds, S. (1978). Theories of Reference and Truth. Erkenntnis, 13(1), pp. 111-129.

Lynch, M. (2004). La importancia de la verdad. (Trad. P. Hermida). Barcelona: Paidós.

Meléndez, R. (2002). La noción de verdad como correspondencia: entre lo trivial y lo metafísico. Ideas y valores, 51(120), pp. 121-128.

Quine, W.V.O. (1990). Pursuit of Truth. Cambridge, Mass.: Harvard University Press.

Ramsey, F.P. (1927). La naturaleza de la verdad. (Trad. M.J. Frápolli). M.J. Frápolli \& J.A. Nicolás. (Eds.), Teorías contemporáneas de la verdad (pp. 117134). Madrid: Tecnos.

Rorty, R. (1994). Verdad y progreso. (Trad. Á. Faerna). Barcelona: Paidós.

Russell, B. (1966). Ensayos Filosóficos. (Trad. J. Capella). Barcelona: Altaya.

Russell, B. (1912). Los problemas de la filosofía. (Trad. J. Xirau). Barcelona: Labor. 
Strawson, P.F. (1950). Verdad. (Trad. A. García). M.J. Frápolli \& J.A. Nicolás. (Eds.), Teorias contemporáneas de la verdad (pp. 307-333). Madrid: Tecnos. Schroeder, M. (2008). What is the Frege-Geach Problem? Philosophy Compass, 3/4, pp. 703-720.

Tarski, A. (1944). La concepción semántica de la verdad y los fundamentos de la semántica. (Trad. E. Colombo). M.J. Frápolli \& J.A. Nicolás. (Eds.), Teorías contemporáneas de la verdad (pp. 57-98). Madrid: Tecnos.

Williams, C.F. (1976). What is Truth? Cambridge: Cambridge University Press.

Wittgenstein, L. (1922). Tractatus Logico-Philosophicus. (Trad. J. Muñoz \& I. Reguera). Madrid: Alianza.

Wright, C. (1992). Truth and Objectivity. Cambridge, Mass. Harvard University Press. 